\title{
Nuclear magnetic resonance spectroscopy to investigate the association between milk metabolites and udder quarter health status in dairy cows
}

\author{
T. Bobbo, ${ }^{1 *} \odot$ G. Meoni, ${ }^{2,3 *} \odot$ G. Niero, ${ }^{1} \dagger \odot$ L. Tenori, ${ }^{2,3} \odot$ C. Luchinat, ${ }^{2,3}$ M. Cassandro, ${ }^{1,4} \odot$ and M. Penasa ${ }^{1} \odot$ \\ ${ }^{1}$ Department of Agronomy, Food, Natural resources, Animals and Environment, University of Padova, 35020 Legnaro (PD), Italy \\ ${ }^{2}$ Magnetic Resonance Center (CERM) and Department of Chemistry "Ugo Schiff," University of Florence, 50019 Sesto Fiorentino, Italy \\ ${ }^{3}$ Consorzio Interuniversitario Risonanze Magnetiche Metallo Proteine (CIRMMP), 50019 Sesto Fiorentino, Italy \\ ${ }^{4}$ Associazione Nazionale Allevatori della Razza Frisona, Bruna e Jersey Italiana, 26100 Cremona (CR), Italy
}

\begin{abstract}
Nuclear magnetic resonance spectroscopy was applied to investigate the association between milk metabolome and udder quarter health status in dairy cows. Mammary gland health status was defined by combining information provided by traditional somatic cell count (SCC) and differential SCC (DSCC), which expresses the percentage of neutrophils and lymphocytes over total SCC. Quarter milk samples were collected in triplicate (d 1 to 3) from 10 Simmental cows, 5 defined as cases and 5 defined as controls according to SCC levels at d 0 . A total of 120 samples were collected and analyzed for bacteriology, milk composition, SCC, DSCC, and milk metabolome. Bacteriological analysis revealed the presence of mostly coagulase-negative staphylococci in quarter milk samples of cows defined as cases. Nuclear magnetic resonance spectra of all quarter samples were first analyzed using the unsupervised multivariate approach principal component analysis, which revealed a specific metabolomic fingerprint of each cow. Then, the supervised cross-validated orthogonal projections to latent structures discriminant analysis unquestionably showed that each cow could be very well identified according to its milk metabolomic fingerprint (accuracy $=95.8 \%$ ). The comparison of 12 different models, built on bucketed 1-dimensional NOESY spectra (noesygppr1d, Bruker BioSpin) using different SCC and DSCC thresholds, corroborated the assumption of improved udder health status classification ability by joining information provided by both SCC and DSCC. Univariate analysis performed on the 34 quantitated metabolites revealed lower levels of riboflavin, galactose, galactose1-phosphate, dimethylsulfone, carnitine, hippurate,
\end{abstract}

Received June 22, 2021.

Accepted August 25, 2021.

*These authors contributed equally to this work.

†Corresponding author: g.niero@unipd.it orotate, lecithin, succinate, glucose, and lactose, and greater levels of lactate, phenylalanine, choline, acetate, O-acetylcarnitine, 2-oxoglutarate, and valine, in milk samples with high somatic cells. In the 5 cases, results of the udder quarter with the highest SCC compared with its symmetrical relative were in line with quarterlevel findings. Our study suggests that increased SCC is associated with changes in milk metabolite fingerprint and highlights the potential use of different metabolites as novel indicators of udder health status and milk quality.

Key words: nuclear magnetic resonance, metabolome, mastitis, biomarker

\section{INTRODUCTION}

In recent decades, the ability to monitor udder health in lactating cows, especially in terms of mastitis and milk somatic cells, has become one of the key points for the entire dairy chain. This issue is of particular interest for (1) farmers, to increase profit through milk quality payment systems and reduction of veterinary interventions; (2) processing industries, as optimal cheese-making properties and cheese yields are favored by low milk somatic cells; and (3) consumers, due to increased sensibility and awareness toward animal health and welfare (Halasa et al., 2007).

In general, mastitis can be diagnosed in 2 main forms. The first, namely clinical mastitis, is accompanied by typical inflammation symptoms at udder level (swelling, redness, and pain) and visual alteration of secreted milk (clumpy, watery, bloody, or yellowish). Pathogens are usually found in the milk of cows with clinical mastitis, together with augmented SCC and altered milk composition (Xi et al., 2017). The second, namely subclinical mastitis, is an inflammation without evident symptoms on mammary gland or visual indicators in milk. Inflammation may occur even without detection of the presence of intramammary pathogens; nonetheless, subclinical mastitis is associated with increased 
milk SCC and decreased milk yield and quality (Xi et al., 2017).

In these circumstances, the development of large-scale tools for identification of animals affected by subclinical mastitis is of great interest, as this would help farmers in the management of this disease and in the prevention of serious clinical outcomes. For this purpose, milk SCC has been widely adopted as an indicator to screen for subclinical mastitis at population level (Harmon, 2001; Pyörälä, 2003) and to perform indirect selection for animals endowed with lower susceptibility toward mastitis (Weigel and Shook, 2018). Most recently, differential somatic cell count (DSCC), which expresses the percentage of neutrophils and lymphocytes over total SCC, has been proposed as a novel trait to screen for udder health on a wide scale (Damm et al., 2017). Joint SCC and DSCC information provide a more detailed depiction of dairy cows' udder health status, which allows identification of healthy cows with greater accuracy, and also to distinguish susceptible animals from those with acute or chronic mastitis (Bobbo et al., 2020).

The analysis of metabolome through proton nuclear magnetic resonance $\left({ }^{1} \mathbf{H} \mathbf{~ N M R}\right)$ spectroscopy has been extensively adopted in the field of human medicine to identify candidate biomarkers able to discriminate between healthy and diseased organs or tissues, and ultimately to develop specific fine-tuned diagnostic tests (Emwas et al., 2013; Meoni et al., 2019). Such know-how and expertise have been transferred to the fields of veterinary and animal sciences (Jones and Cheung, 2007; Caboni et al., 2017; Basoglu at al., 2020). In the case of bovine milk, previous authors have hypothesized that the metabolome is likely the result of different sources of metabolites released into milk by microorganisms (Hettinga et al., 2008; Hettinga et al., 2009), live or dead immune cells (Azzara and Dimick, 1985), blood (Basoglu et al., 2018), and mammary epithelial cells (Shennan and Peaker, 2000). Milk and dairy products' metabolomes have been studied in relation to animal health, milk quality, geographical origin, and cheese-making processes (Tenori et al., 2018; Scano et al., 2019). In particular, the study of the metabolic profile of cow milk with high and low SCC is a quite novel approach in the livestock sector, which is shedding light on the physiologic pathways at the basis of mastitis onset (Sundekilde et al., 2013).

To the authors' knowledge there is still a lack of studies investigating the metabolomic profile of milk with high and low SCC and DSCC, especially at udder quarter level. This research question is addressed in the present study, which aimed at investigating the association between milk metabolome and udder quarter health status in dairy cows through an NMR-based approach.

\section{MATERIALS AND METHODS}

\section{Animal Enrollment and Sampling Procedures}

The experimental procedures used in this trial were performed during routine milking procedures and were not invasive; therefore, animal welfare committee authorization was not required. Milk samples were collected from Simmental cows of the experimental farm of the University of Padova (Legnaro, Italy). Animals were housed in freestall barns, fed TMR, and milked twice a day, in the morning $(0600 \mathrm{~h})$ and in the evening (1800 $\mathrm{h}$ ). The study was designed to collect information (stage of lactation and parity order) of the lactating cows that were present in the herd at the day of the first visit (d 0 ) and to characterize their daily milk production and composition. Samples collected in the morning milking of $d 0$ were analyzed the same day in the laboratory of the Breeders Association of Veneto Region (Padova, Italy) for fat, protein, casein, and lactose percentages using a MilkoScan FT6000 (Foss Analytical A/S); and SCC (cells/mL) and DSCC (\%) using a Fossomatic 7 DC (Foss Analytical A/S). Among the 26 lactating cows present in the herd at d 0, 5 cows with the highest SCC values were defined as cases (SCC between 114,000 and 193,000 cells $/ \mathrm{mL}$ ), and 5 cows with the lowest SCC values were chosen as controls (SCC between 7,000 and 33,000 cells $/ \mathrm{mL}$ ). Out of the 26 cows, 3 were previously treated for mastitis with antibiotics and were excluded from the trial to avoid any possible effect on milk metabolites. Among the remaining 23 cows, the 5 animals selected as cases were those with the highest SCC. By contrast, because we had different cows with similar low SCC value, controls were selected to maintain a similar average parity and DIM values compared with cases: 219 DIM (103-356) and 3.8 parities (2-6) for cases, and 155 DIM (70-219) and 3.4 parities (2-5) for controls. In the 3 subsequent days (d 1-3), milk samples were collected during morning milking at quarter level from the 5 cases and the 5 controls (40 quarters were sampled each day for a total of 120 samples across the $3 \mathrm{~d}$ ). Sampling protocol was as follows: (1) after cleaning the teats with individual disposable towels and discarding the first streams of milk, sterile quarter milk samples were collected for bacteriological analysis; (2) quarters were drained simultaneously using a vacuum system connected to 4 different buckets (Figure 1); (3) after milking, each bucket was weighted to obtain individual milk production. From each bucket, multiple milk aliquots of $50 \mathrm{~mL}$ were collected. 


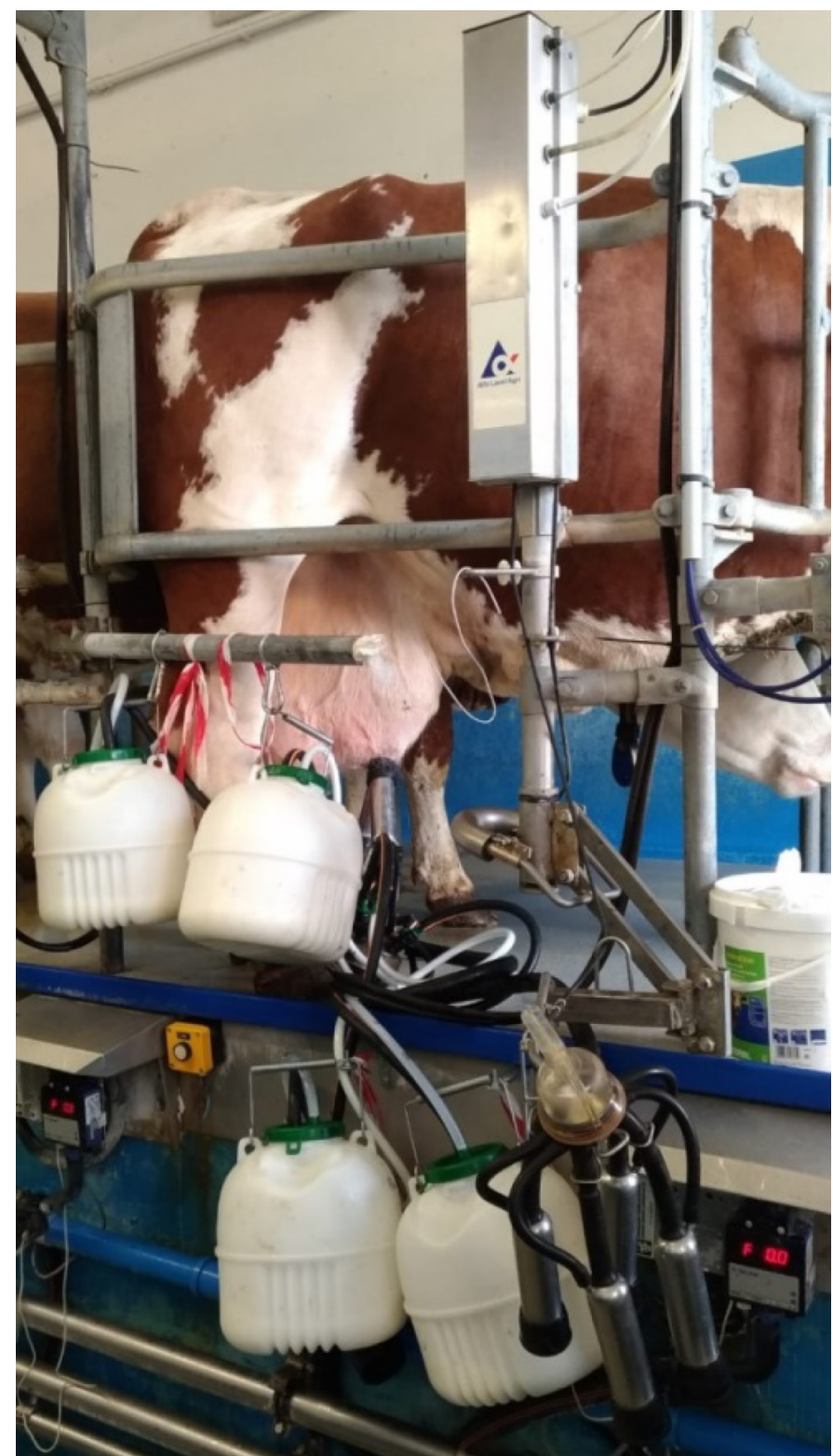

Figure 1. Vacuum system connected to 4 different buckets used in the study to simultaneously drain the 4 quarters.

\section{Milk Bacteriological Analysis and Milk Composition}

The first milk aliquot was used for bacteriological examination, which was performed in the laboratory of the Istituto Zooprofilattico Sperimentale delle Venezie (Legnaro, Italy). Samples were cultured and identified according to National Mastitis Council guidelines (NMC, 1999). Briefly, $10 \mu \mathrm{L}$ of each quarter milk sample were cultured on the surface of $5 \%$ sheep blood agar and MacConkey agar plates, followed by incubation at $37^{\circ} \mathrm{C}$ for 16 to $24 \mathrm{~h}$. Bacteria were identified according to NMC (1999), which includes morphology, Gram staining, catalase and coagulase reactions, oxidase reaction, biochemical properties, and hemolysis pattern. Gram-positive bacteria were differentiated as staphylococci and streptococci by the catalase reaction. The coagulase tube test in rabbit plasma was used to distinguish Staphylococcus aureus from CNS. Gram-negative bacteria were identified by oxidase test as well as by growth features on MacConkey agar and eosin methylene blue agar. A sample was considered contaminated when 3 or more dissimilar colony types were observed with no single colony type predominating (NMC, 1999).

The second milk aliquot was transferred at $4^{\circ} \mathrm{C}$ to the laboratory of the Breeders Association of Veneto Region (Padova, Italy). Milk samples were warmed at room temperature, gently mixed by inversion and analyzed within $12 \mathrm{~h}$ for fat, protein, casein, and lactose (\%) using a MilkoScan FT6000 (Foss Analytical A/S). Somatic cell count (cell/mL) and DSCC (\%) were determined using the Fossomatic 7 DC (Foss Analytical A/S).

\section{Nuclear Magnetic Resonance}

The third aliquot of milk was set aside for NMR analysis. Milk samples were dissolved in dichloromethane $\left(\mathrm{CH}_{2} \mathrm{Cl}_{2}\right), 1: 1$ (vol/vol; Tenori et al., 2018). The mixture was homogenized by vortexing and then was incubated for $10 \mathrm{~min}$ at room temperature. The mixture was then centrifuged at $5,000 \times g$ at $4^{\circ} \mathrm{C}$ for 30 min, and $350 \mu \mathrm{L}$ of the supernatant were added to 350 $\mu \mathrm{L}$ of sodium phosphate buffer $\left[70 \mathrm{mM} \mathrm{Na} \mathrm{NPO}_{4} ; 20 \%\right.$ (vol/vol) $\mathrm{H}_{2} \mathrm{O}, 6.1 \mathrm{mM} \mathrm{NaN}$; $4.6 \mathrm{~m} M$ sodium trimeth-

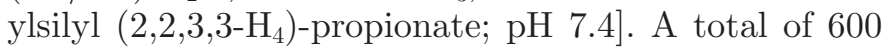
$\mu \mathrm{L}$ of this mixture was transferred into a $5-\mathrm{mm}$ NMR tube (Bruker BioSpin) and stored at $-80^{\circ} \mathrm{C}$ for the subsequent analysis performed at the Magnetic Resonance Center (Sesto Fiorentino, Italy).

One-dimensional (1D) ${ }^{1} \mathrm{H}$ NMR spectra of milk extracts were recorded on a Bruker spectrometer operating at $600.13 \mathrm{MHz}$ proton Larmor frequency and equipped with a 5 -mm PATXI ${ }^{1} \mathrm{H}_{-}-{ }^{13} \mathrm{C}_{-}{ }^{15} \mathrm{~N}$ probe including a z-axis gradient coil, automatic tuning-matching, and an automatic refrigerated sample changer (SampleJet). A BTO 2000 thermocouple provided temperature stabilization at the level of approximately $0.1 \mathrm{~K}$ at the sample. Before measurement, samples were kept for at least 5 min inside the NMR probe for temperature equilibration (310 K). For each sample two $1 \mathrm{D}^{1} \mathrm{H}$ NMR spectra were acquired with NOESY sequence (noesygppr1d, Bruker BioSpin), using 64 scans, $98 \mathrm{k}$ data point, a spectral width of $18,028 \mathrm{~Hz}$, an acquisition time of 
$2.7 \mathrm{~s}$, a relaxation delay of $4 \mathrm{~s}$, and a mixing time of $10 \mathrm{~ms}$. Both molecules with low molecular weight and macromolecules are visible in 1D NOESY spectra.

Free induction decays were multiplied by an exponential function equivalent to a $0.3-\mathrm{Hz}$ line-broadening factor before applying Fourier transformation. Transformed spectra were automatically corrected for phase and baseline distortions using TopSpin (Bruker). The $\alpha$-lactose doublet $\left(5.24 \delta^{1} \mathrm{H} \mathrm{ppm}\right)$ was used to calibrate spectra. For multivariate analysis, each 1D spectrum in the range between 0.02 and $10.00 \delta^{1} \mathrm{H} \mathrm{ppm}$ was segmented into $0.02-\delta^{1} \mathrm{H}$ ppm chemical shift bins (buckets). The water $\left(4.61-4.77 \delta^{1} \mathrm{H} \mathrm{ppm}\right)$ and dichloromethane (5.30-5.33 and 5.42-5.65 $\left.\delta^{1} \mathrm{H} \mathrm{ppm}\right)$ regions were removed from the buckets of NOESY spectra. Normalization using probabilistic quotient normalization was applied to the bins before any statistical analysis. A total of 34 metabolites were identified in the NMR spectra. Signal identification was performed using a library of NMR spectra of pure organic compounds (Assure NMR 2.2 software, Bruker BioSpin), public databases (FooDB, https://foodb.ca/, and Milk Composition Database, http://www.mcdb.ca/) storing references, and literature data (Tenori et al., 2018). The resulting matrix was used to perform univariate data analyses.

\section{Statistical Analyses}

All data analyses were performed using $\mathrm{R}$ (version 3.5.3; R Core Team, 2020), an open-source software for statistical analysis. Principal component analysis was used as the first exploratory unsupervised analysis at quarter level. Orthogonal projections to latent structures discriminant analysis, applied to quarter data, was chosen as a supervised technique to extract latent and hidden variation characteristics of udder health status. The accuracies and the confusion matrices for the different cows (Animal ID) classifications were assessed by means of 100 cycles of a Monte Carlo cross-validation scheme ( $\mathrm{R}$ script developed in-house). In this case, $90 \%$ of the data were randomly chosen at each iteration as a training set to build the model. Then the remaining $10 \%$ were tested, and sensitivity, specificity, and accuracy of the classification were assessed. Two sets of analyses were performed, depending on whether the aim was to classify animals or single quarters. In the first case all samples collected from cows defined as cases (or controls) were labeled as cases (or controls); that is, all samples from quarters of the same cow were treated the same. This strategy was chosen to distinguish diseased animals from healthy ones. In the other cases individual quarters were classified as high or low risk of mastitis, depending on selected thresholds of SCC and DSCC in the collected samples. The accuracies and the confusion matrices reported for the classification of samples collected from case or control cows, and for quarters of cows at low or high risk of mastitis based on several SCC and DSCC thresholds were assessed using a cross-validation scheme. In this procedure a validation set was iteratively created by randomly removing from the training set all the 4 samples belonging to the same cow, to avoid a classification bias due to the similarity of the samples from the same animal. Then the classification model was built on the training set, and the removed samples were used to assess the model performances by generating a confusion matrix that expresses sensitivity, specificity, and accuracy. The whole procedure was repeated 100 times for each model, and the results were averaged.

Univariate analysis was performed on quantitated metabolites. The Wilcoxon test was chosen to assess differences between 2 groups, and false discovery rate correction was applied using the Benjamini and Hochberg correction method. An adjusted $P<0.05$ was considered significant. Furthermore, for each metabolite, the Cliff's delta effect size was calculated by means of the R package "effsize" (Torchiano, 2020).

\section{RESULTS AND DISCUSSION}

\section{Milk Composition, SCC, and DSCC}

Cows defined as cases and controls averaged 12.2 and $12.9 \mathrm{~kg}$ of milk per milking, respectively. Milk of cases was characterized on average by $3.06 \%$ fat, $3.48 \%$ protein, and $4.74 \%$ lactose, with a mean SCC of 187,000 cells $/ \mathrm{mL}$. Controls had average fat, protein, and lactose contents of $2.90 \%, 3.27 \%$, and $4.84 \%$, respectively, and a mean SCC of 21,000 cells $/ \mathrm{mL}$. The effects of high SCC on milk production and composition have been extensively described in the literature (Le Maréchal et al., 2011). Although data on the effects of high SCC on the total content of protein and fat are controversial, a clear decrease of lactose has been reported (Le Maréchal et al., 2011). At the time of analysis, the Fossomatic 7 DC (Foss Analytical A/S) did not provide DSCC values for milk samples with $\mathrm{SCC}<50,000$ cells/ $\mathrm{mL}$, due to accuracy and repeatability issues of the instrument (Damm et al., 2017). Therefore, in samples with SCC $<50,000$ cells $/ \mathrm{mL}$, DSCC was set to $45 \%$ for subsequent analysis, following the approach of Wall et al. (2018) and Bobbo et al. (2020).

\section{Bacteriological Analysis}

Bacteriological analysis revealed the presence of mostly CNS in quarter milk samples of cows defined 
Bobbo et al.: MILK METABOLITES AND UDDER HEALTH

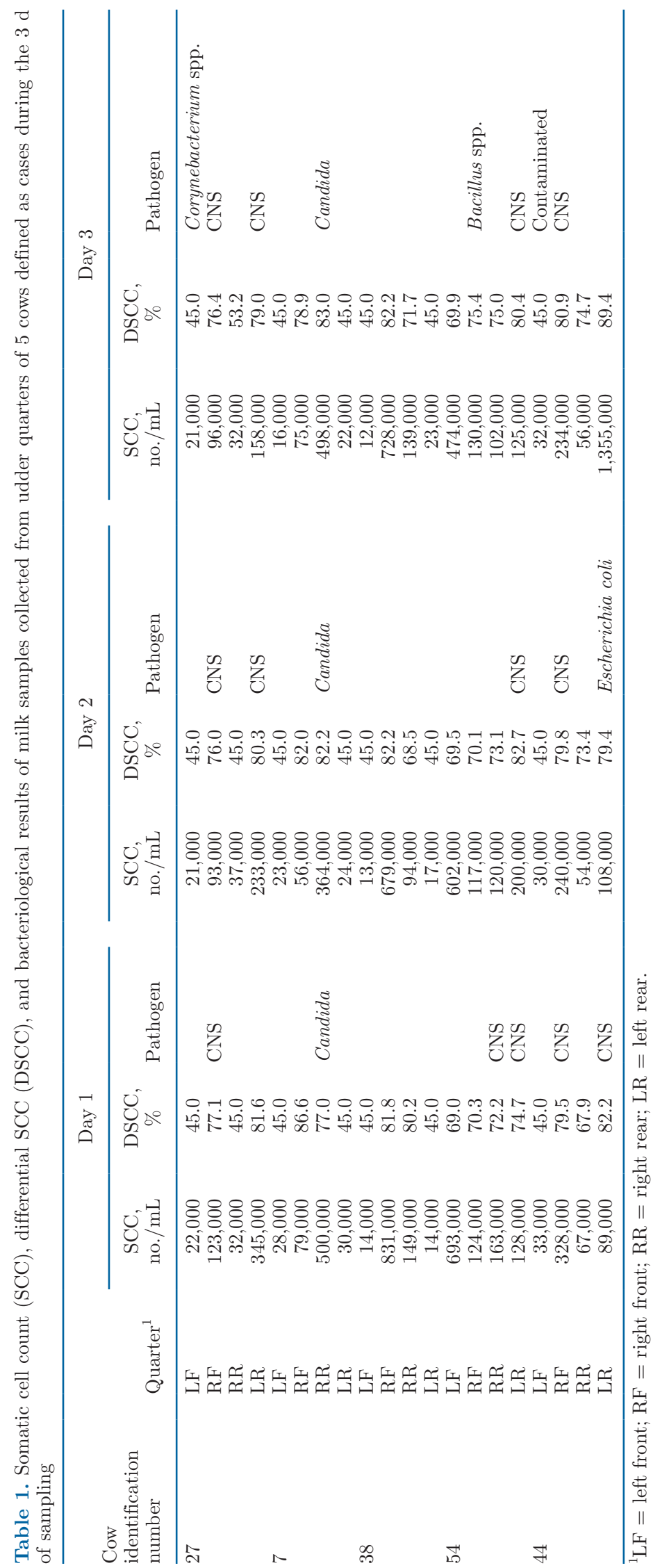


Table 2. Confusion matrix of cross-validated orthogonal projections to latent structures discriminant analysis model built to classify different cows $^{1}$

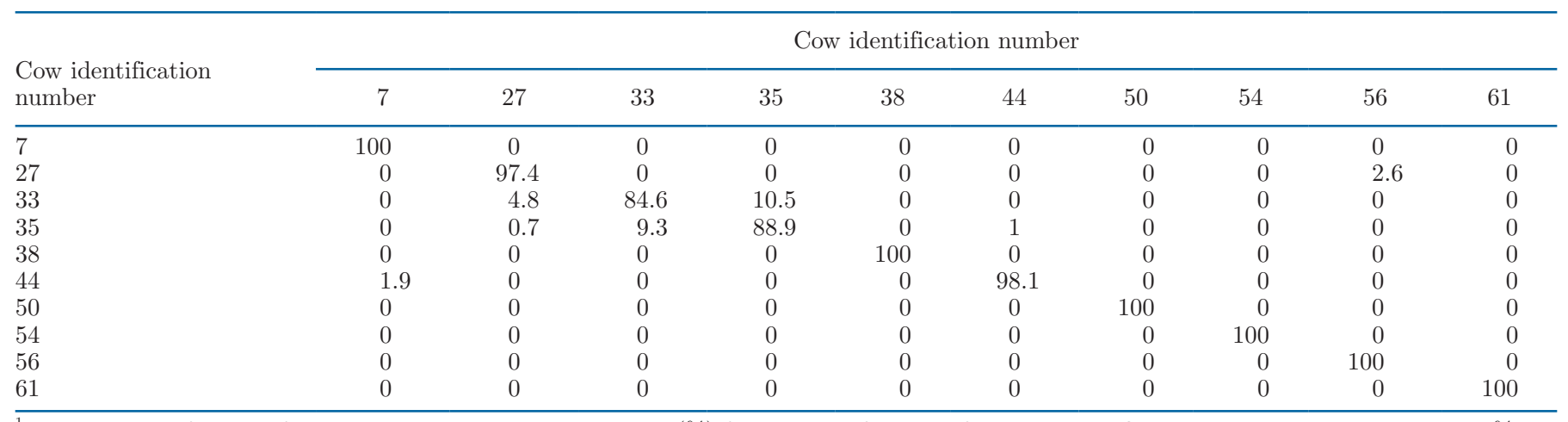

${ }^{1}$ The diagonal of the confusion matrix reports the sensitivity (\%) for the classification of each animal. Overall predictive accuracy $=95.8 \%$.

Udder

$1=\mathrm{LF}$

$2=\mathrm{RF}$

$3=R R$

$4=\mathrm{LR}$

\section{Cow ID}

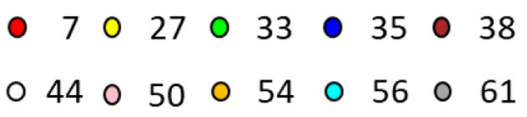

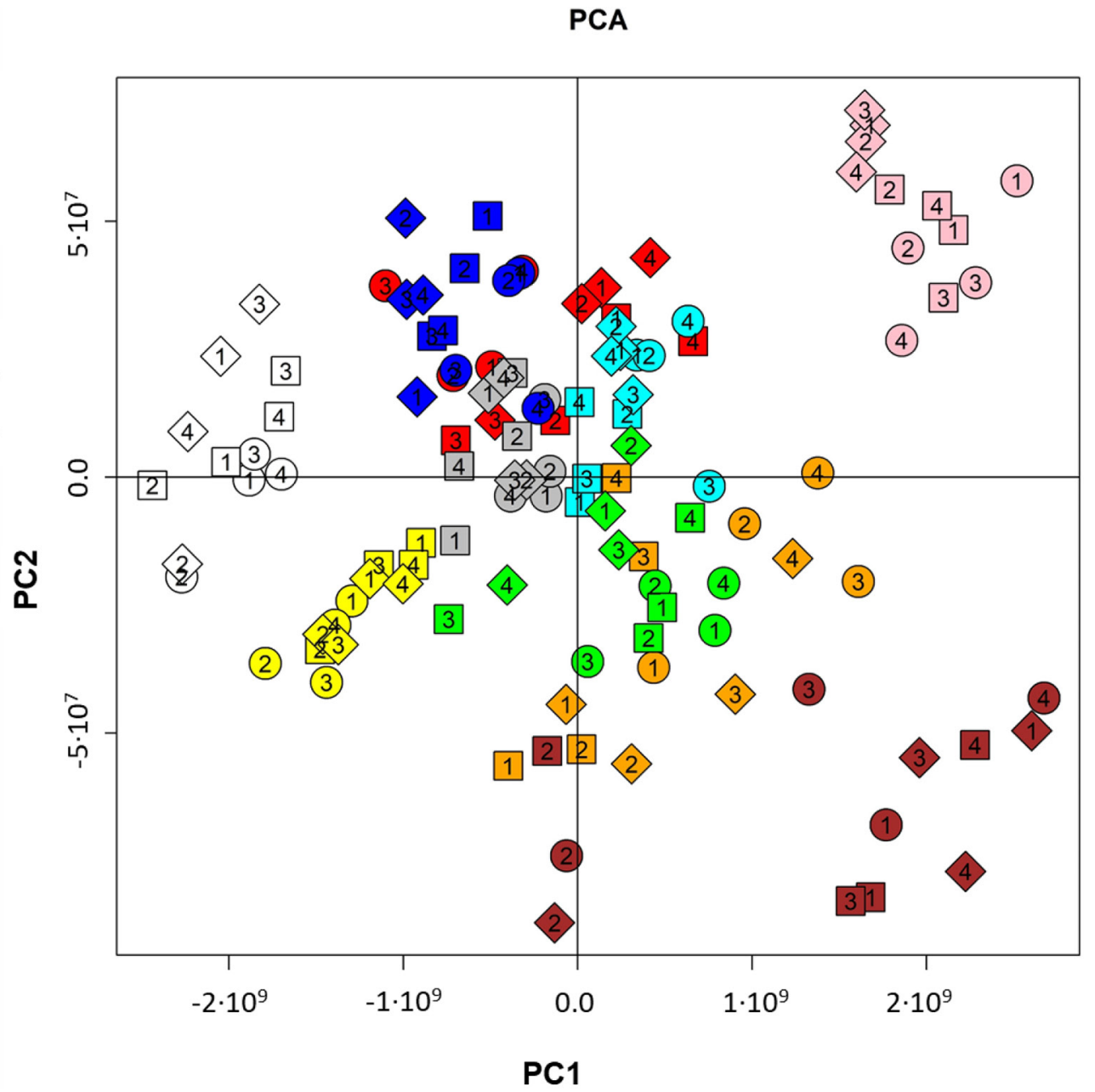

Figure 2. Principal component analysis (PCA) score plot of milk nuclear magnetic resonance (NMR) spectra. Each dot represents an NMR milk spectrum. Colors describe different cows (Cow ID), and udder quarters are numbered from 1 to 4, starting from the left front, clockwise up to the left rear. $\mathrm{LF}=$ left front; $\mathrm{RF}=$ right front; $\mathrm{RR}=$ right rear; $\mathrm{LR}=$ left rear. Days of milk sampling are coded with different symbols: first day of sampling, circles; second day of sampling, squares; third day of sampling, diamonds. PC1 = principal component 1 ; PC2 = principal component 2 . 
as cases (Table 1). In particular, CNS strains were detected in at least 2 out of 3 consecutive quarter samples in 3 cows. In this regard, the National Mastitis Council guidelines recommend that the same pathogen be isolated from 2 out of 3 samples before labeling a quarter as positive (Oliver et al., 2004). Previous studies (Tomazi et al., 2015; Bobbo et al., 2017) reported that intramammary infections caused by CNS had no detrimental influence on milk production. Indeed, minor pathogens cause less damages to the udder tissue than major pathogens, such as Staphylococcus aureus, Escherichia coli, Streptococcus spp., and Klebsiella spp. (Reyher et al., 2012). One cow was infected with yeast of the genus Candida, and in another cow no bacterial growth was observed, despite the relatively high SCC and DSCC values in both front and rear quarters of the right side (Table 1). According to Bobbo et al. (2017), the absence of bacterial growth in milk samples with high SCC can have 2 possible explanations: (1) the cow was in the healing process, so even if the inflammatory response was still active (high SCC), the pathogens were already spontaneously cleared (Smith et al., 1985); or (2) the inflammatory process was at the maximum level, and the pathogens, engulfed by phagocytes, could not be isolated (Newbould and Neave, 1965). Contagious pathogens were not detected. Results from the control group are summarized in Supplemental Table S1 (https://doi.org/10.6084/m9.figshare.16670497.v1).

\section{OPLS-DA}

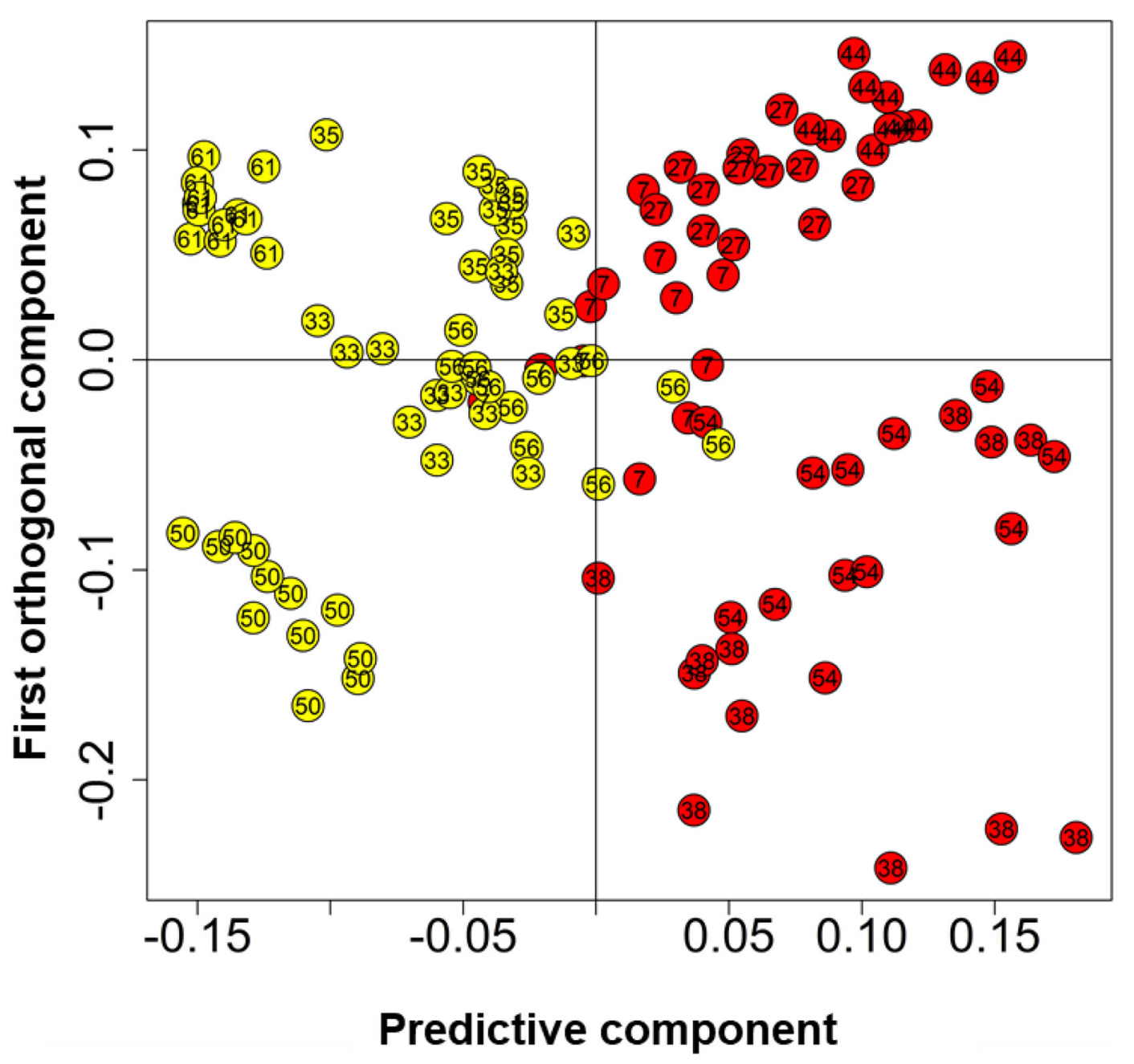

Figure 3. Score plot of a cross-validated orthogonal projections to latent structures discriminant analysis (OPLS-DA) model built on bucketed one-dimensional NOESY spectra (noesygppr1d, Bruker BioSpin). The model was trained to discriminate milk samples classified as controls (in yellow, $\mathrm{n}=60$ ) from those classified as cases (in red, $\mathrm{n}=60$ ). 


\section{Classification of Samples and Cows Based on NMR Spectra}

Nuclear magnetic resonance spectra (buckets) of all 120 quarter milk samples were first analyzed using the unsupervised multivariate approach principal component analysis to gain an overview of the samples under study and possibly identify outliers. As shown in Figure 2 , the principal component analysis score plot on 1D NOESY revealed a specific metabolomic fingerprint of different cows corresponding to cow ID (each animal is coded with a specific color). Then, cross-validated orthogonal projections to latent structures discriminant analysis was applied as a supervised method to determine the classification accuracy for each animal, based on their ${ }^{1} \mathrm{H}$ NMR spectra, collected at 3 different time points for each udder quarter (Table 2). For the 10 animals we obtained an average individual discrimination accuracy of $95.8 \%$ (range $84.6-100 \%$ ). This result unquestionably shows that each cow can be very well identified according to its milk metabolomic fingerprint.

Subsequently, the orthogonal projections to latent structures discriminant analysis approach was employed to extract latent and hidden variation characteristics of the health status of cows and individual udder quarters. First, we tried to classify udder quarters of animals pre- viously defined as cases from those defined as controls, treating all quarters of the same animal as cases or controls (Figure 3; Table 3, model 1). Second, we tried to classify individual quarters of animals according to their SCC, choosing 100,000 and 200,000 cells/mL as thresholds to create distinct groups (Table 3, models 2 and 3): quarters of cows at low risk $(<100,000$ and $<200,000$ cells $/ \mathrm{mL})$ and at high risk $(\geq 100,000$ and $\geq 200,000$ cells $/ \mathrm{mL}$ ) of developing mastitis. Finally, we tried to classify quarters of animals according to their DSCC, choosing 50, 60, 65, 70, and $80 \%$ as thresholds to create the 2 groups described (Table 3, models 4-8). Among the models tested, model 3 was the most accurate $(76.8 \%)$ to discriminate milk samples of cows at low or high mastitis risk based on an SCC threshold of 200,000 cells $/ \mathrm{mL}$, suggesting a major influence of this trait on the metabolomic profile of the cow's milk. Our findings further support the 200,000 cells/mL cutoff as the optimal threshold to minimize udder health classification errors (Dohoo and Leslie, 1991; Schukken et al., 2003). By contrast, models built to discriminate udder health status according to DSCC values were unable to correctly classify milk samples. Furthermore, a model to discriminate milk samples with DSCC $>80 \%$ from milk samples with DSCC $<50 \%$ was attempted without reaching a satisfactory discrimination (accu-

Table 3. Cross-validated orthogonal projections to latent structures discriminant analysis models built on bucketed one-dimensional NOESY spectra (noesygppr1d, Bruker BioSpin)

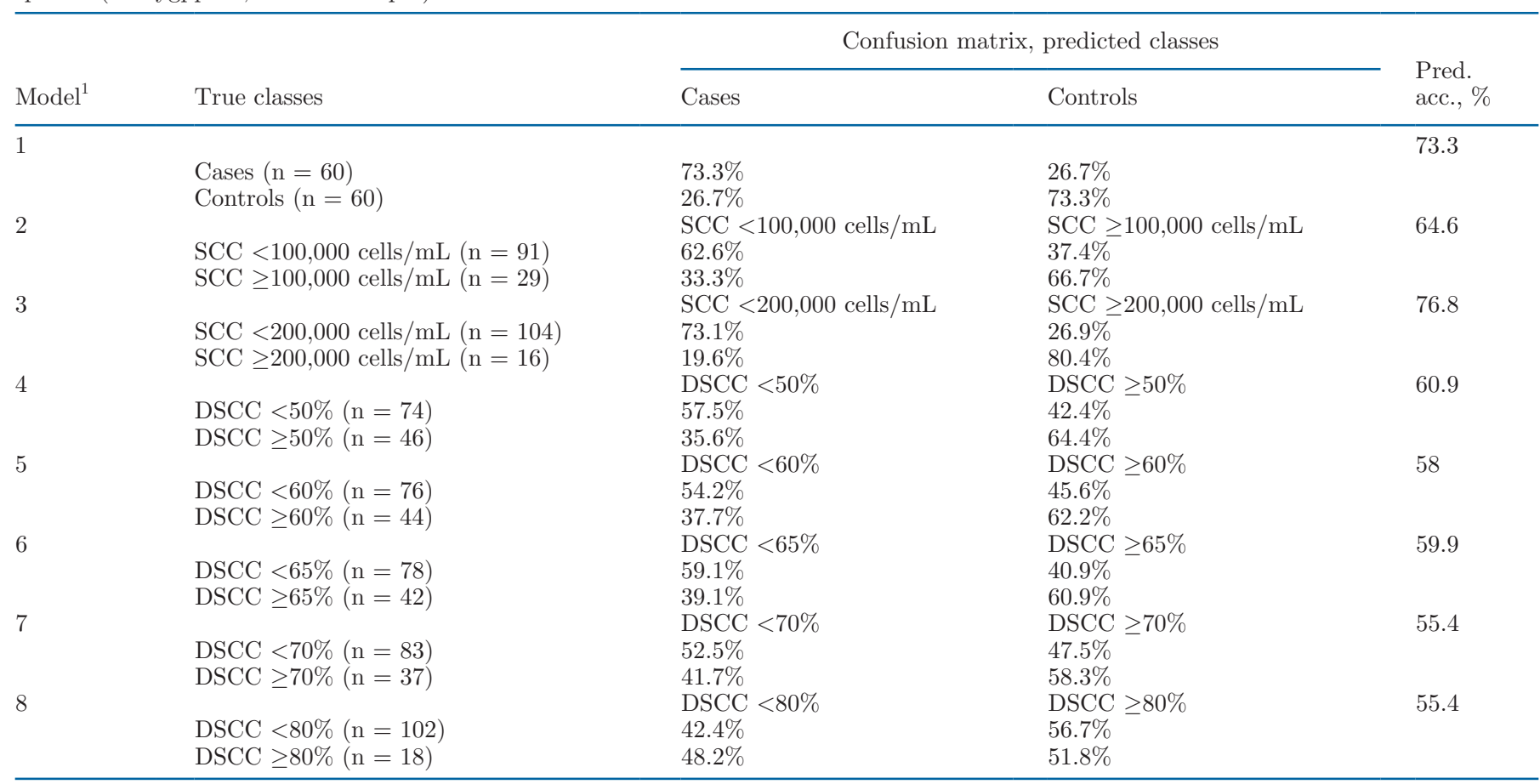

${ }^{1}$ Model 1: confusion matrix and predictive accuracy (pred. acc.) of the model trained to discriminate controls from cases. Models 2 and 3: confusion matrices and predictive accuracies of models built to predict milk samples below or above predefined SCC thresholds. Models 4-8: confusion matrices and predictive accuracies of models built to predict milk samples below or above predefined differential SCC (DSCC) thresholds. 


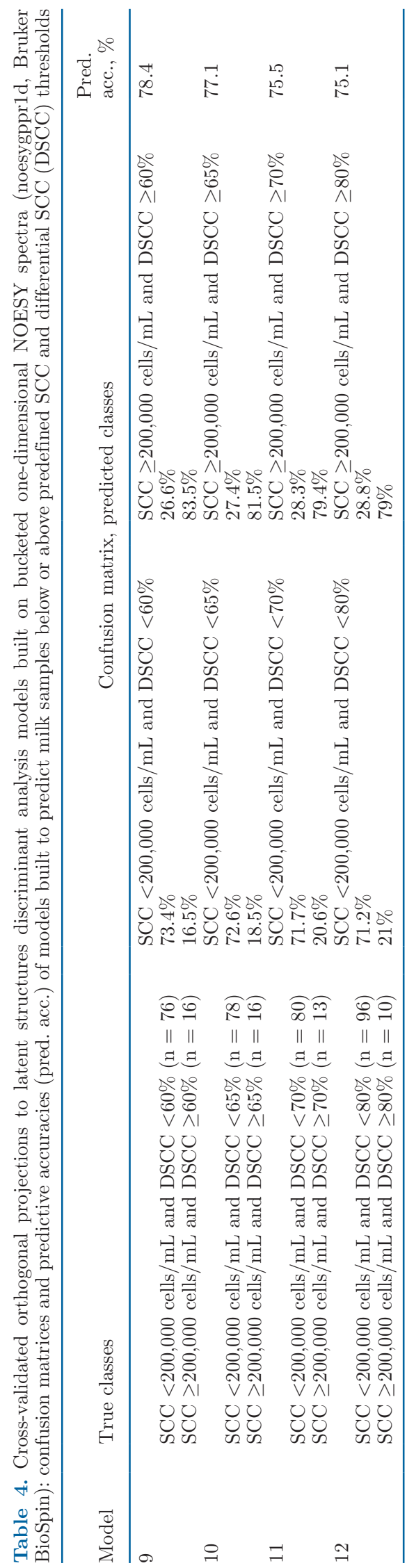

racy: 60\%). Four additional models (Table 4, models 9-12) were then created by combining the best SCC threshold (200,000 cells/mL) and 4 DSCC thresholds $(60,65,70$, and $80 \%)$. Combining the 2 traits, the most accurate model was model $9(78.4 \%)$, and the increase of DSCC from 60 to $80 \%$ led to a progressive decrease of the accuracy of the models. These findings corroborate the assumption of an improved udder health status classification ability by joining information provided by both SCC and DSCC.

\section{Milk Metabolites in Cows' Udder Quarters with Low or High SCC}

Milk metabolites can originate from different pathways, including (1) release from microorganisms, (2) active secretion or leaking from immune cells, (3) blood transfer, and (4) metabolic activity of mammary epithelial cells (Sundekilde et al., 2013). Indeed, previous research studies have demonstrated the association between presence of bacteria in milk and altered profile in terms of volatile compounds (Hettinga et al., 2009). Also, the number of somatic cells in milk (in quantitative terms) and their specific composition (in qualitative terms) are known as factors affecting the metabolic fingerprint of milk (Sundekilde et al., 2013).

In the present study, 34 metabolites were identified in milk ${ }^{1} \mathrm{H}$ NMR spectra. Univariate analyses were performed to compare metabolite levels in quarter milk samples with $\mathrm{SCC} \geq 200,000$ cells/mL versus samples with SCC $<200,000$ cells $/ \mathrm{mL}$ (Figure 4), and in samples with SCC $\geq 200,000$ cells $/ \mathrm{mL}$ and $\mathrm{DSCC} \geq 60 \%$ versus samples with SCC $<200,000$ cells $/ \mathrm{mL}$ and $\mathrm{DSCC}<60 \%$ (Figure 5). The combination of SCC and DSCC thresholds allowed us to better distinguish healthy quarters (those with low SCC and DSCC) from mastitic quarters (those with high SCC and DSCC), excluding quarters susceptible to mastitis (with low SCC but high DSCC, indicating the presence of increased neutrophils levels, i.e., of an inflammatory response) and chronically inflamed quarters (where high SCC levels are mostly due to a high content of macrophages).

Milk samples with SCC $\geq 200,000$ cells $/ \mathrm{mL}$ were characterized by lower levels of riboflavin, galactose, galactose-1-phosphate, dimethylsulfone, carnitine, hippurate, orotate, lecithin, succinate, glucose, and lactose (Figure 4). Similar findings were observed for milk samples with SCC $\geq 200,000$ cells $/ \mathrm{mL}$ and DSCC $\geq 60 \%$, which were also characterized by lower levels of glutamate compared with milk samples with SCC $<200,000$ cells $/ \mathrm{mL}$ and DSCC $<60 \%$ (Figure 5). By contrast, milk samples with $\mathrm{SCC} \geq 200,000$ cells $/ \mathrm{mL}$ and with combined SCC $\geq 200,000$ cells/mL and DSCC $\geq 60 \%$, had greater levels of lactate, phenylalanine, 
choline, acetate, O-acetylcarnitine, 2-oxoglutarate, and valine compared with milk samples with $\mathrm{SCC}<200,000$ cells/mL (Figure 4; Figure 5). In addition, pairwise univariate analysis was also performed for each of the cows defined as cases, by comparing the udder quarter with the highest SCC (average of the 3 sampling times) with its symmetrical relative (Table 5). Results of withincow analyses were in line with quarter-level findings. In fact, significantly higher levels of lactate, 2-oxoglutarate, malonate, methanol, and phenylalanine were observed in udder quarters with elevated SCC compared with contralateral healthy quarters. Inflamed quarters also showed the lowest levels of lactose, galactose, and orotate.

The results of the present study partially agree with those of Sundekilde et al. (2013), who studied the association between milk metabolites and SCC, considering 2 groups of cows with very low $(<14,000$ cells $/ \mathrm{mL})$ and very high $(>720,000$ cells $/ \mathrm{mL}) \mathrm{SCC}$ in milk. Indeed, decreased hippurate and fumarate levels in milk with high SCC were observed by Sundekilde et al. (2013), although the biochemical and physiological mechanisms underlying this phenomenon are still unclear. In addition, increased levels of lactate, butyrate, isoleucine, acetate, and BHB were reported by the same authors in milk with high SCC. Lactate and acetate, as well as butyrate, have been previously demonstrated to increase in milk with high SCC (Davis et al., 2004; Hettinga et al., 2008; Hettinga et al., 2009; Sundekilde et al., 2013). Indeed, lactate and acetate represent the end products of bacterial metabolism. Dervishi et al. (2017) reported alteration in amino acid metabolism before, during, and after diagnosis of subclinical mastitis in transition dairy cows, and suggested blood serum valine and phenylalanine as good predictors of mastitis. Luangwilai et al. (2021) characterized the metabolite profiles of

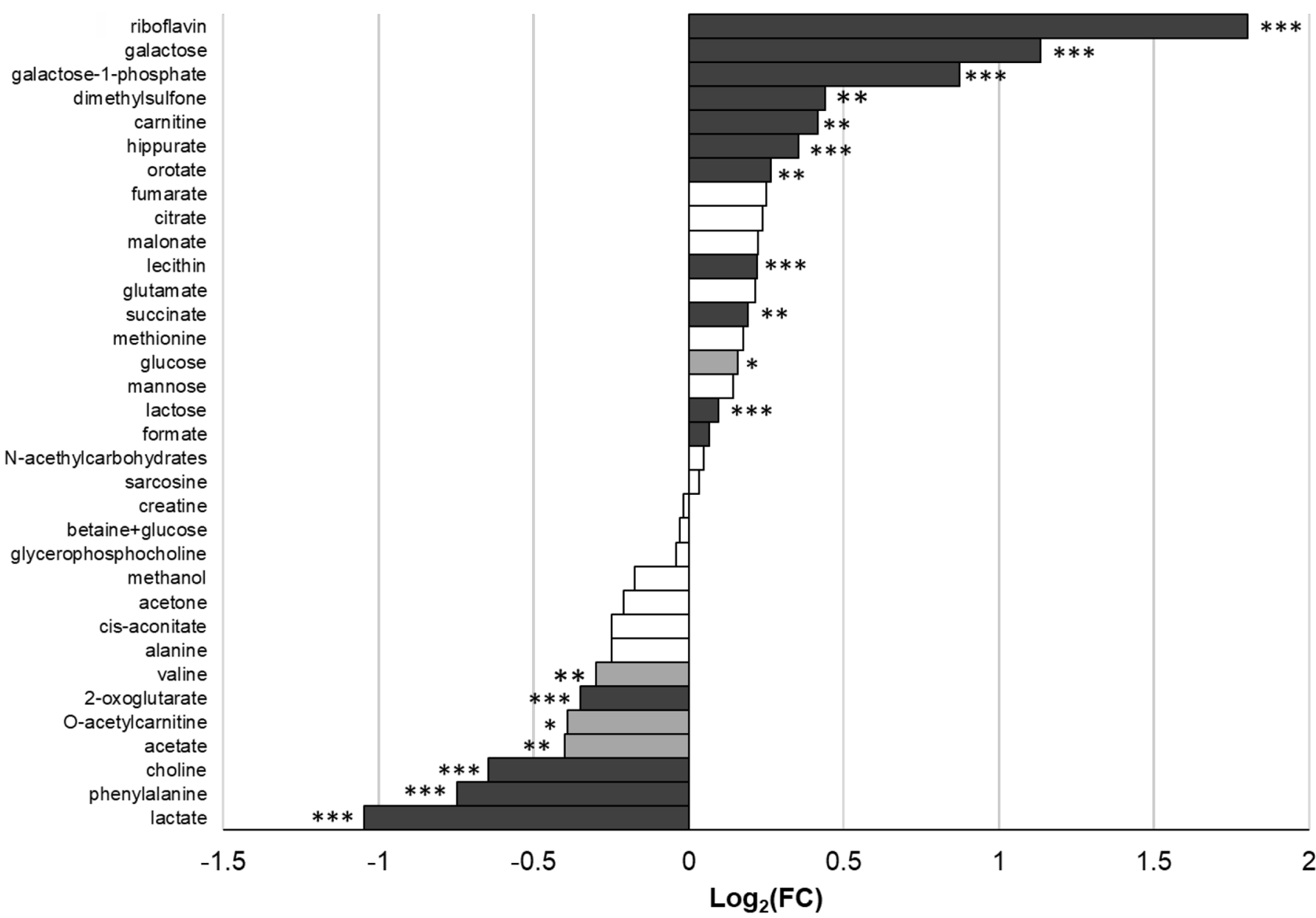

Figure 4. Logarithmic fold change $\left[\log _{2}(\mathrm{FC})\right]$ of identified metabolites. Negative $\log _{2}(\mathrm{FC})$ bars refer to higher metabolite levels in samples with SCC $\geq 200,000$ cells $/ \mathrm{mL}$, and positive $\log _{2}(\mathrm{FC})$ bars refer to lower levels in samples with SCC $\geq 200,000$ cells $/ \mathrm{mL}$. Significant metabolites are colored as light gray $(P<0.05)$ and dark gray $(P<0.05$ and false discovery rate $<0.05)$. Cliff's delta effect size is also reported as large $(* * *)$, medium $(* *)$, or small $(*)$. 


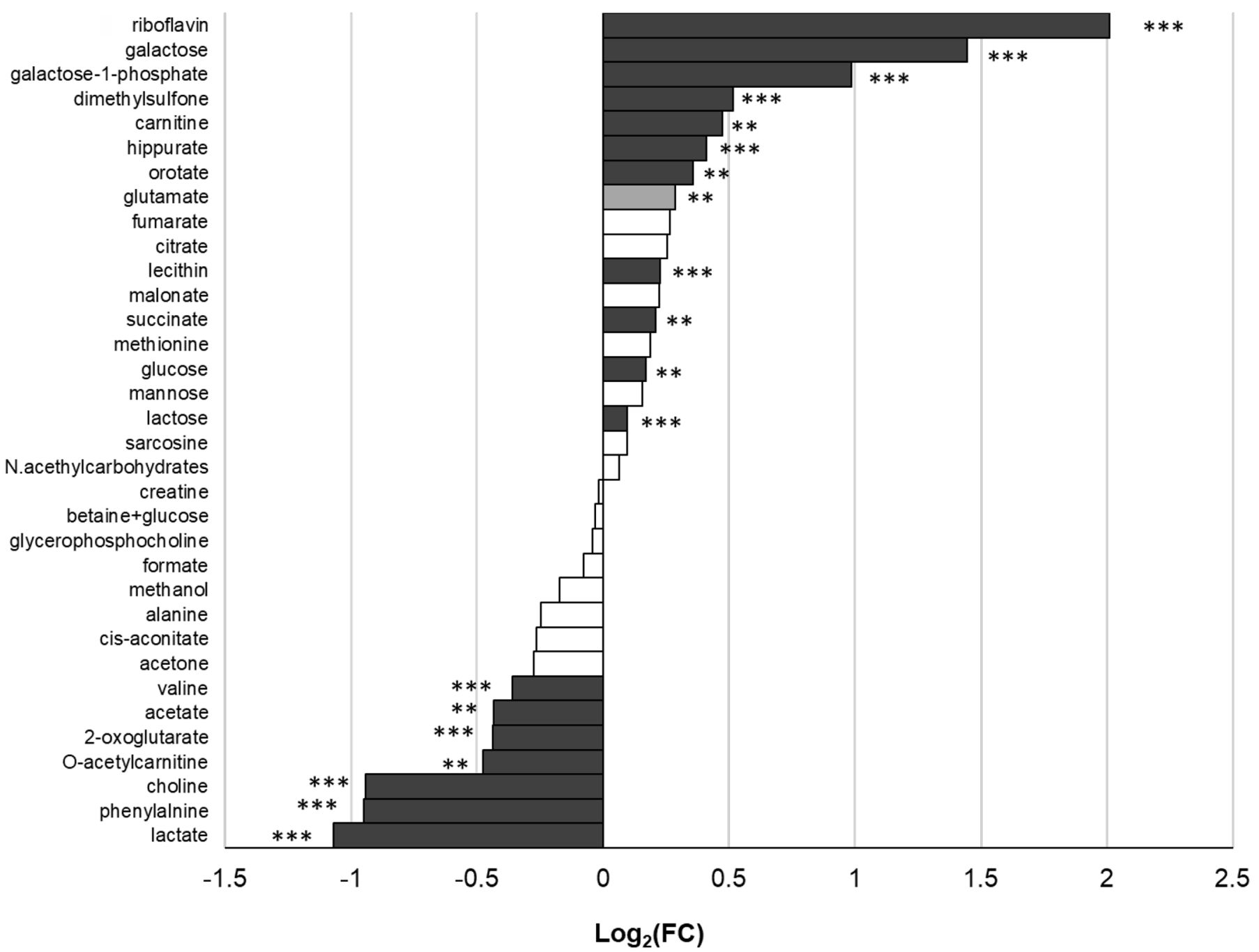

Figure 5. Logarithmic fold change $\left[\log _{2}(\mathrm{FC})\right]$ of identified metabolites. Negative $\log _{2}(\mathrm{FC})$ bars refer to higher metabolite levels in samples with SCC $\geq 200,000$ cells $/ \mathrm{mL}$ and differential SCC (DSCC) $\geq 60 \%$, and positive $\log _{2}(\mathrm{FC}$ ) bars refer to lower levels in samples with SCC $\geq 200,000$ cells $/ \mathrm{mL}$ and DSCC $\geq 60 \%$. Significant metabolites are colored as light gray $(P<0.05)$ and dark gray $(P<0.05$ and false discovery rate $<0.05)$. Cliff's delta effect size is also reported as large $(* * *)$ or medium $(* *)$.

milk samples collected from healthy cows and animals affected by subclinical and clinical mastitis using an ${ }^{1} \mathrm{H}-\mathrm{NMR}$ metabolomic approach. Lactate, acetate, valine, and phenylalanine were suggested as potential biomarkers for diagnosing mastitis, as a significant rise in their levels in milk was observed in raw milk of cows with clinical and subclinical mastitis. In our study, a lower riboflavin (vitamin $\mathrm{B}_{2}$ ) content was detected in milk of cows with high SCC. In a previous study, intramuscular injection of vitamin $B_{2}$ has been reported to stimulate neutrophil function and phagocytic bactericidal activity (Osame et al., 1995). In addition, intravenous injection of vitamin $B_{2}$ in cows with high milk SCC led to a rapid decrease of SCC in udder quarters infected by Staphylococcus aureus (Sato et al., 1999).
Although the process underlying the SCC decrease following injection of vitamin $B_{2}$ is not yet clear, the activation of host-defense mechanisms against bacterial infection in the mammary gland seems to be involved, including regulation of cytokine production (Sato et al., 1999). The decreased orotate content in milk with high SCC reported in the present study is in contrast with findings of Karatas et al. (2008), who reported that milk orotate level increased in cows affected by subclinical mastitis. Lower levels of glutamate in highSCC milk can be related to its use by the immune system, which requires a supply of glutamine for lymphocyte proliferation and cytokine production (Chang et al., 1999; Newsholme, 2001). In addition, glutamate metabolism has been demonstrated to be altered by 
Table 5. Pairwise calculation of Wilcoxon $P$-values and false discovery rates

\begin{tabular}{|c|c|c|c|}
\hline Metabolite & $P$-value & $\begin{array}{c}\text { False } \\
\text { discovery } \\
\text { rate }\end{array}$ & Level $^{1}$ \\
\hline$\overline{\text { Valine }}$ & $6.8 \times 10^{-1}$ & 0.768 & \\
\hline Lactate & $6.10 \times 10^{-5}$ & $0.001^{*}$ & $\uparrow$ \\
\hline Alanine & $1.35 \times 10^{-1}$ & 0.224 & \\
\hline Acetate & $2.29 \times 10^{-1}$ & 0.34 & \\
\hline$N$-Acetyl carbohydrates & $1.81 \times 10^{-2}$ & 0.059 & \\
\hline Methionine & $7.20 \times 10^{-1}$ & 0.793 & \\
\hline 2-Oxoglutarate & $2.62 \times 10^{-3}$ & $0.015^{*}$ & $\uparrow$ \\
\hline Acetone & $8.90 \times 10^{-1}$ & 0.890 & \\
\hline Glutamate & $3.59 \times 10^{-1}$ & 0.482 & \\
\hline Carnitine & $4.54 \times 10^{-1}$ & 0.558 & \\
\hline Succinate & $9.46 \times 10^{-2}$ & 0.177 & \\
\hline Citrate & $9.46 \times 10^{-2}$ & 0.177 & \\
\hline Sarcosine & $2.15 \times 10^{-2}$ & 0.062 & \\
\hline Creatine & $3.59 \times 10^{-1}$ & 0.482 & \\
\hline Malonate & $6.10 \times 10^{-5}$ & $0.001 *$ & $\uparrow$ \\
\hline Lecithin & $2.15 \times 10^{-2}$ & 0.062 & \\
\hline Dimethyl sulfone & $4.21 \times 10^{-1}$ & 0.537 & \\
\hline O-Acetylcarnitine & $1.51 \times 10^{-1}$ & 0.241 & \\
\hline Choline & $8.04 \times 10^{-1}$ & 0.864 & \\
\hline Glycerophosphocholine & $3.89 \times 10^{-1}$ & 0.507 & \\
\hline Glucose & $4.13 \times 10^{-2}$ & 0.093 & \\
\hline Betaine+glucose & $1.21 \times 10^{-1}$ & 0.207 & \\
\hline Methanol & $6.71 \times 10^{-3}$ & $0.032^{*}$ & $\uparrow$ \\
\hline Mannose & $3.02 \times 10^{-2}$ & 0.076 & \\
\hline Lactose & $6.10 \times 10^{-4}$ & $0.005^{*}$ & $\downarrow$ \\
\hline Galactose & $2.62 \times 10^{-3}$ & $0.014^{*}$ & $\downarrow$ \\
\hline Galactose-1-phosphate & $1.88 \times 10^{-1}$ & 0.288 & \\
\hline Cis-aconitate & $2.56 \times 10^{-2}$ & 0.069 & \\
\hline Orotate & $1.03 \times 10^{-2}$ & $0.040^{*}$ & $\downarrow$ \\
\hline Fumarate & $6.37 \times 10^{-2}$ & 0.130 & \\
\hline Phenylalanine & $3.05 \times 10^{-4}$ & $0.004^{*}$ & $\uparrow$ \\
\hline Hippurate & $1.81 \times 10^{-2}$ & 0.059 & \\
\hline Riboflavin & $1.03 \times 10^{-1}$ & 0.184 & \\
\hline Formate & $8.90 \times 10^{-1}$ & 0.890 & \\
\hline
\end{tabular}

${ }^{1}$ Upward arrows $(\uparrow)$ indicate higher metabolites levels in quarters with high SCC; downward arrows $(\downarrow)$ indicate lower levels in quarters with high SCC.

$* P<0.05$.

subclinical mastitis caused by Streptococcus agalactiae (Tong et al., 2019). In the present study, decreased lactose content in milk with high SCC was confirmed by both chemical and NMR analyses. This phenomenon is well described in the literature. Indeed, in concurrence with high SCC and inflammation, the functionality of mammary cell membranes is altered: blood constituents flow into the milk, and lactose is decreased as a result of (1) augmented transfer from milk to blood, to keep osmotic pressure constant, and (2) lower biosynthesis at the mammary gland level (Costa et al., 2019). Changes in carbohydrate metabolism during mammary gland inflammation can further explain lower levels of galactose, galactose-1-phosphate, and glucose. A correlation between variation in the levels of lactose, choline, carnitine, and citrate, and milk technological properties has been reported in a previous study with an NMR- based metabolomic approach (Sundekilde et al., 2011). In particular, a tendency toward a higher citrate concentration in samples with poor clotting ability, as well as a higher choline concentration and lower carnitine concentration in good-coagulating milk samples, have been observed. Although the important role of choline and carnitine in nutrition is well established, little is known about the effects of choline and carnitine on milk coagulation properties, as well as on udder health status. For the remaining milk metabolites, comparison with literature was not possible, due to the lack of studies that have investigated the variations of such molecules in relation to udder health.

\section{CONCLUSIONS}

Our study suggests that increased SCC is associated with changes in the milk metabolite fingerprint. In particular, NMR-based metabolomics reveals that the levels of several metabolites (e.g., riboflavin, galactose, galactose-1-phosphate, dimethylsulfone, carnitine, hippurate, orotate, lecithin, succinate, glucose, lactose, lactate, phenylalanine, choline, acetate, O-acetylcarnitine, 2-oxoglutarate, and valine) are significantly different in milks characterized by low or high SCC. Our findings confirm the role of lactose as a possible biomarker for subclinical mastitis screening and highlight the possible use of other metabolites as novel indicators of udder health status and milk quality. Results of the present study are a first step for the development of rapid cowside tests able to detect milk metabolites, which have been shown to vary significantly according to SCC. The possibility of collecting such phenotypes during routine recording procedures would allow consideration of these traits for breeding purposes. Further studies are required to better elucidate the relationship between milk metabolites and SCC, as well as the role of specific metabolites in association with animal physiology.

\section{ACKNOWLEDGMENTS}

This research was funded by the Ministry of Agricultural, Food and Forestry Policies (Rome, Italy) through the project "CowSens - Sensoristica applicata al miglioramento della gestione alimentare, salute animale e della produzione casearia nella vacca da latte" (CowSens ID17, CUP: C24I19000840001). Staff of the experimental farm "Lucio Toniolo" of the University of Padova (Legnaro, Italy), Alberto Simonetto (University of Padova, Legnaro, Italy) and Enrico Borgato (University of Padova, Legnaro, Italy) are gratefully acknowledged for technical support. The authors have not stated any conflicts of interest. 


\section{REFERENCES}

Azzara, C. D., and P. S. Dimick. 1985. Lipolytic enzyme activity of macrophages in bovine mammary gland secretions. J. Dairy Sci. 68:1804-1812. https://doi.org/10.3168/jds.S0022-0302(85)81030 -4 .

Basoglu, A., N. Baspinar, L. Tenori, C. Licari, and E. Gulersoy. 2020. Nuclear magnetic resonance (NMR)-based metabolome profile evaluation in dairy cows with and without displaced abomasum. Vet. Q. 40:1-15. https://doi.org/10.1080/01652176.2019.1707907.

Basoglu, A., I. Sen, G. Meoni, L. Tenori, and A. Naseri. 2018. NMRbased plasma metabolomics at set intervals in newborn dairy calves with severe sepsis. Mediators Inflamm. 2018:1-12. https:// doi.org/10.1155/2018/8016510.

Bobbo, T., M. Penasa, and M. Cassandro. 2020. Combining total and differential somatic cell count to better assess the association of udder health status with milk yield, composition and coagulation properties in cattle. Ital. J. Anim. Sci. 19:697-703. https://doi .org/10.1080/1828051X.2020.1784804.

Bobbo, T., P. L. Ruegg, G. Stocco, E. Fiore, M. Gianesella, M. Morgante, D. Pasotto, G. Bittante, and A. Cecchinato. 2017. Association between pathogen-specific cases of subclinical mastitis and milk yield, quality, protein composition, and cheese-making traits in dairy cows. J. Dairy Sci. 100:4868-4883. https://doi.org/10 $.3168 /$ jds.2016-12353.

Caboni, P., C. Manis, I. Ibba, M. Contu, V. Coroneo, and P. Scano. 2017. Compositional profile of ovine milk with a high somatic cell count: A metabolomics approach. Int. Dairy J. 69:33-39. https:// doi.org/10.1016/j.idairyj.2017.02.001.

Chang, W. K., K. D. Yang, and M. F. Shaio. 1999. Effect of glutamine on Th1 and Th2 cytokine responses of human peripheral blood mononuclear cells. Clin. Immunol. 93:294-301. https://doi.org/10 $.1006 / \mathrm{clim} .1999 .4788$.

Costa, A., N. Lopez-Villalobos, N. W. Sneddon, L. Shalloo, M. Franzoi, M. De Marchi, and M. Penasa. 2019. Invited review: Milk lactose - Current status and future challenges in dairy cattle. J. Dairy Sci. 102:5883-5898. https://doi.org/10.3168/jds.2018-15955.

Damm, M., C. Holm, M. Blaabjerg, M. N. Bro, and D. Schwarz. 2017. Differential somatic cell count-A novel method for routine mastitis screening in the frame of Dairy Herd Improvement testing programs. J. Dairy Sci. 100:4926-4940. https://doi.org/10.3168/ jds.2016-12409.

Davis, S. R., V. C. Farr, C. G. Prosser, G. D. Nicholas, S. A. Turner, J. Lee, and A. L. Hart. 2004. Milk L-lactate concentration is increased during mastitis. J. Dairy Res. 71:175-181. https://doi.org/ 10.1017/S002202990400007X.

Dervishi, E., G. Zhang, S. M. Dunn, R. Mandal, D. S. Wishart, and B. N. Ametaj. 2017. GC-MS metabolomics identifies metabolite alterations that precede subclinical mastitis in the blood of transition dairy cows. J. Proteome Res. 16:433-446. https://doi.org/10 .1021/acs.jproteome.6b00538.

Dohoo, I. R., and K. E. Leslie. 1991. Evaluation of changes in somatic cell counts as indicators of new intramammary infections. Prev. Vet. Med. 10:225-237. https://doi.org/10.1016/0167 $-5877(91) 90006-\mathrm{N}$.

Emwas, A. H. M., R. M. Salek, J. L. Griffin, and J. Merzaban. 2013. NMR-based metabolomics in human disease diagnosis: Applications, limitations, and recommendations. Metabolomics 9:10481072. https://doi.org/10.1007/s11306-013-0524-y.

Halasa, T., K. Huijps, O. Østerås, and H. Hogeveen. 2007. Economic effects of bovine mastitis and mastitis management: A review. Vet. Q. 29:18-31. https://doi.org/10.1080/01652176.2007.9695224.

Harmon, R. J. 2001. Somatic cell counts: A primer. Pages 3-9 in Proc. Natl. Mastitis Council 40th Annual Meeting, Feb. 11-14, 2001 Reno, NV. National Mastitis Council.

Hettinga, K. A., H. J. F. van Valenberg, T. J. G. M. Lam, and A. C. M. van Hooijdonk. 2008. Detection of mastitis pathogens by analysis of volatile bacterial metabolites. J. Dairy Sci. 91:3834-3839. https://doi.org/10.3168/jds.2007-0941.

Hettinga, K. A., H. J. F. van Valenberg, T. J. G. M. Lam, and A. C. M. van Hooijdonk. 2009. The origin of the volatile metabolites found in mastitis milk. Vet. Microbiol. 137:384-387. https://doi .org/10.1016/j.vetmic.2009.01.016.

Jones, O. A., and V. L. Cheung. 2007. An introduction to metabolomics and its potential application in veterinary science. Comp. Med. 57:436-442.

Karatas, F., S. Aydin, F. Kaygusuzoglu, H. Yildiz, F. A. Erulas, and Y. Ozkan. 2008. Ghrelin and orotic acid increased in subclinical mastitis. Arch. Physiol. Biochem. 114:178-182. https://doi.org/10 $.1080 / 13813450802180940$.

Le Maréchal, C., R. Thiéry, E. Vautor, and Y. Le Loir. 2011. Mastitis impact on technological properties of milk and quality of milk products-A review. Dairy Sci. Technol. 91:247-282. https://doi .org/10.1007/s13594-011-0009-6.

Luangwilai, M., K. Duangmal, N. Chantaprasarn, and S. Settachaimongkon. 2021. Comparative metabolite profiling of raw milk from subclinical and clinical mastitis cows using $1 \mathrm{H}-\mathrm{NMR}$ combined with chemometric analysis. Int. J. Food Sci. Technol. 56:493-503. https://doi.org/10.1111/ijfs.14665.

Meoni, G., S. Lorini, M. Monti, F. Madia, G. Corti, C. Luchinat, A. L. Zignego, L. Tenori, and L. Gragnani. 2019. The metabolic fingerprints of HCV and HBV infections studied by nuclear magnetic resonance spectroscopy. Sci. Rep. 9:4128. https://doi.org/10.1038/ s41598-019-40028-4.

National Mastitis Council (NMC). 1999. Laboratory Handbook on Bovine Mastitis. NMC.

Newbould, F. H. S., and F. K. Neave. 1965. The recovery of small numbers of Staphylococcus aureus infused into the bovine teat cistern. J. Dairy Res. 32:157-162. https://doi.org/10.1017/ S0022029900018483.

Newsholme, P. 2001. Why is L-glutamine metabolism important to cells of the immune system in health, postinjury, surgery or infection? J. Nutr. 131:2515S-2522S. https://doi.org/10.1093/jn/131.9 $.2515 \mathrm{~S}$.

Oliver, S. P., R. N. Gonzalez, and J. S. Hogan. 2004. Microbiological Procedures for the Diagnosis of Bovine Udder Infection and Determination of Milk Quality. 4th ed. National Mastitis Council.

Osame, S., S. Araki, and M. Kimura. 1995. Effects of vitamin $B_{2}$ on neutrophil functions in cattle. J. Vet. Med. Sci. 57:493-495. https: //doi.org/10.1292/jvms.57.493.

Pyörälä, S. 2003. Indicators of inflammation in the diagnosis of mastitis. Vet. Res. 34:565-578. https://doi.org/10.1051/vetres:2003026.

R Core Team. 2020. R: A language and environment for statistical computing. R Foundation for Statistical Computing. May 20, 2021. https://www.R-project.org/.

Reyher, K. K., I. R. Dohoo, D. T. Scholl, and G. P. Keefe. 2012. Evaluation of minor pathogen intramammary infection, susceptibility parameters, and somatic cell counts on the development of new intramammary infections with major mastitis pathogens. J. Dairy Sci. 95:3766-3780. https://doi.org/10.3168/jds.2011-5148.

Sato, S., H. Hori, and K. Okada. 1999. Effect of vitamin $B_{2}$ on somatic cell counts in milk of clinical Staphylococcus aureus mastitis. J. Vet. Med. Sci. 61:569-571. https://doi.org/10.1292/jvms.61.569.

Scano, P., E. Cusano, P. Caboni, and R. Consonni. 2019. NMR metabolite profiles of dairy: A review. Int. Dairy J. 90:56-67. https:/ /doi.org/10.1016/j.idairyj.2018.11.004.

Schukken, Y. H., D. J. Wilson, F. Welcome, L. Garrison-Tikofsky, and R. N. Gonzalez. 2003. Monitoring udder health and milk quality using somatic cell counts. Vet. Res. 34:579-596. https://doi.org/10 .1051/vetres:2003028.

Shennan, D. B., and M. Peaker. 2000. Transport of milk constituents by the mammary gland. Physiol. Rev. 80:925-951. https://doi.org/ 10.1152/physrev.2000.80.3.925.

Smith, K. L., D. A. Todhunter, and P. S. Schoenberger. 1985. Environmental mastitis: Cause, prevalence, prevention. J. Dairy Sci. 68:1531-1553. https://doi.org/10.3168/jds.S0022-0302(85)80993 $-0$.

Sundekilde, U. K., P. D. Frederiksen, M. R. Clausen, L. B. Larsen, and H. C. Bertram. 2011. Relationship between the metabolite profile and technological properties of bovine milk from two dairy breeds elucidated by NMR-based metabolomics. J. Agric. Food Chem. 59:7360-7367. https://doi.org/10.1021/jf202057x. 
Sundekilde, U. K., N. A. Poulsen, L. B. Larsen, and H. C. Bertram. 2013. Nuclear magnetic resonance metabolomics reveals strong association between milk metabolites and somatic cell count in bovine milk. J. Dairy Sci. 96:290-299. https://doi.org/10.3168/ jds.2012-5819.

Tenori, L., C. Santucci, G. Meoni, V. Morrocchi, G. Matteucci, and C. Luchinat. 2018. NMR metabolomic fingerprinting distinguishes milk from different farms. Food Res. Int. 113:131-139. https://doi .org/10.1016/j.foodres.2018.06.066.

Tomazi, T., J. L. Gonçalves, J. R. Barreiro, M. A. Arcari, and M. V. dos Santos. 2015. Bovine subclinical intramammary infection caused by coagulase-negative staphylococci increases somatic cell count but has no effect on milk yield or composition. J. Dairy Sci. 98:3071-3078. https://doi.org/10.3168/jds.2014-8466.

Tong, J., H. Zhang, Y. Zhang, B. Xiong, and L. Jiang. 2019. Microbiome and metabolomic analysis of milk from dairy cows with subclinical streptococcus agalactiae mastitis-Potential biomarkers. Front. Microbiol. 10:2547. https://doi.org/10.3389/fmicb.2019 .02547 .

Torchiano, M. 2017. Package "effsize". Accessed June 18, 2021. https:/ /cran.r-project.org/web/packages/effsize/effsize.pdf.

Wall, S. K., O. Wellnitz, R. Bruckmaier, and D. Schwarz. 2018. Differential somatic cell count in milk before, during, and after lipopoly- saccharide- and lipoteichoic-acid-induced mastitis in dairy cows. J. Dairy Sci. 101:5362-5373. https://doi.org/10.3168/jds.2017-14152.

Weigel, K. A., and G. E. Shook. 2018. Genetic selection for mastitis resistance. Vet. Clin. North Am. Food Anim. Pract. 34:457-472. https://doi.org/10.1016/j.cvfa.2018.07.001.

Xi, X., L. Y. Kwok, Y. Wang, C. Ma, Z. Mi, and H. Zhang. 2017. Ultra-performance liquid chromatography-quadrupole-time of flight mass spectrometry MSE-based untargeted milk metabolomics in dairy cows with subclinical or clinical mastitis. J. Dairy Sci. 100:4884-4896. https://doi.org/10.3168/jds.2016-11939.

\section{ORCIDS}

T. Bobbo ำ https://orcid.org/0000-0003-0328-8903

G. Meoni $\odot$ https://orcid.org/0000-0002-8608-4641

G. Niero $\odot$ https://orcid.org/0000-0002-6169-1162

L. Tenori ๑ https://orcid.org/0000-0001-6438-059X

M. Cassandro @ https://orcid.org/0000-0002-8709-2870

M. Penasa @ https://orcid.org/0000-0001-9984-8738 